\title{
Информация о XVI международном совещании по геологии россыпей и месторождений кор выветривания (РКВ-2020) «Россыпи и месторождения кор выветривания XXI века: задачи, проблемы, решения»
}

\author{
(С2021 А. Д. Савко ${ }^{凶}$, М. Ю. Овчинникова \\ Воронеэсский государственный университет, \\ Университетская пл., 1, 394018, Воронеж, Российская Федерация
}

\begin{abstract}
Для цитирования: Савко А. Д., Овчинникова М. Ю. Информация о XVI международном совещании по геологии россыпей и месторождений кор выветривания (РКВ-2020) «Россыпи и месторождения кор выветривания XXI века: задачи, проблемы и решения» // Вестник Воронежского государственного университета. Серия: Геология. 2021. №4. С. 88-93. DOI: https://doi.org/10.17308/geology.2021.4/3794
\end{abstract}

\section{Information on the 16th International Meeting on the Geology of Placers and Weathering Crust Deposits (RKV-2020) «Placers and Weathering Crust Deposits of the 21st Century: Challenges, Problems, and Solutions»}

\author{
(C)2021 A. D. Savko ${ }^{\varpi}$, M. Yu. Ovchinnikova
}

Voronezh State University, 1 Universitetskaya pl., Voronezh 394018, Russian Federation

For citation: Savko A. D., Ovchinnikova M. Yu. Information on the 16th International Meeting on the Geology of Placers and Weathering Crust Deposits (RKV-2020) «Placers and Weathering Crust Deposits of the 21st Century: Challenges, Problems, and Solutions».Vestnik Voronezhskogo gosudarstvennogo universiteta. Seriya: Geologiya - Proceedings of Voronezh State University. Series: Geology, 2021, no. 4, pp. 88-93. DOI: https://doi.org/10.17308/geology.2021.4/3794

Conflict of interests: The authors declare the absence of obvious and potential conflicts of interest related to the publication of this article.

В период с 13-18.09.2021 на базе Воронежского государственного университета (Россия) проходило XVI Международное совещание по геологии россыпей и кор выветривания «Россыпи и месторождения кор выветривания: задачи, проблемы. Решения». Совещание было запланировано на 2020 г., но в связи с пандемией Ковид-19 было перенесено на 2021 г.
Совещания по геологии россыпей и месторождений кор выветривания (РКВ) проводятся в стране с декабря 1959 г. один раз в четыре года. Инициатором Совецания РКВ являлся академик Н. А. Шило - организатор академической науки и производств, связанных с разработкой россыпей, на востоке страны. За свою 62-летнию историю Совещания проводили во многих регио-

\footnotetext{
$\square$ Савко Аркадий Дмитриевич, e-mail: savko@geol.vsu.ru
} 
нах Советского Союза и России при участии ведущих специалистов мира по геологии и технологиям отработки россыпей. Председателем Программного комитета XVI Международного совещания являлся академик, член президиума РАН, научный руководитель ИГЕМ РАН Н. С. Бортников.

Цель XVI Международного Совещания - обсуждение новейших достижений и анализ приоритетных направлений развития геологии россыпей и месторождений кор выветривания, техногенно-минеральных образований в части современных методов изучения, освоения и решения геолого-минералогических, экономических, экологических и технологических проблем в изучении, поисках и освоении; обмен идеями и опытом; расширение сотрудничества между производственными предприятиями и научными центрами в целях эффективного развития данной актуальной области знаний.

В совещании приняли участие 105 человек из восьми стран (Россия, Казахстан, Украина, Узбекистан, Азербайджан, Киргизия, Канада, Зимбабве). Это представители академических и отраслевых институтов, учебных заведений и производственных организаций, в том числе 33 участника из зарубежных стран. Состоялись три однодневные экскурсии на карьеры гранитов с россыпями во вскрыше близ г. Павловска (Воронежская) (рис.1), Лебединский железных руд (Белгородская области) (рис. 2), Латненский огнеупорных глин (под Воронежем) (рис. 3).

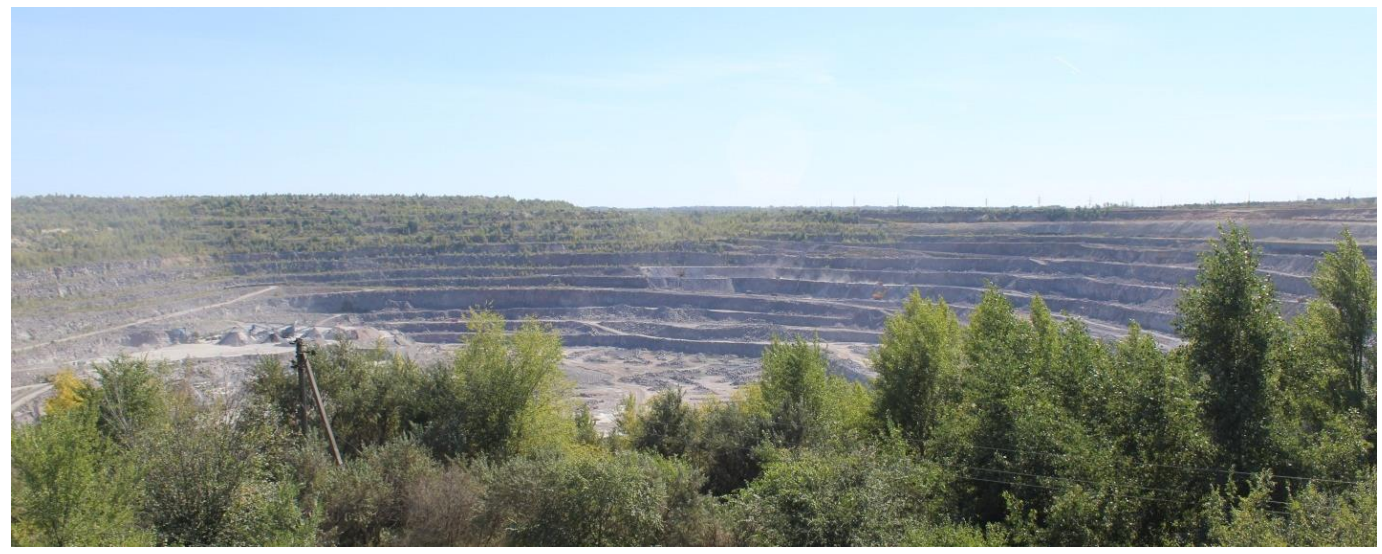

Рис. 1. Экскурсия для участников совещания на Павловский гранитный карьер (Воронежская область). Fig. 1. Excursion for the meeting participants to the Pavlovsky granite quarry (Voronezh Region).]
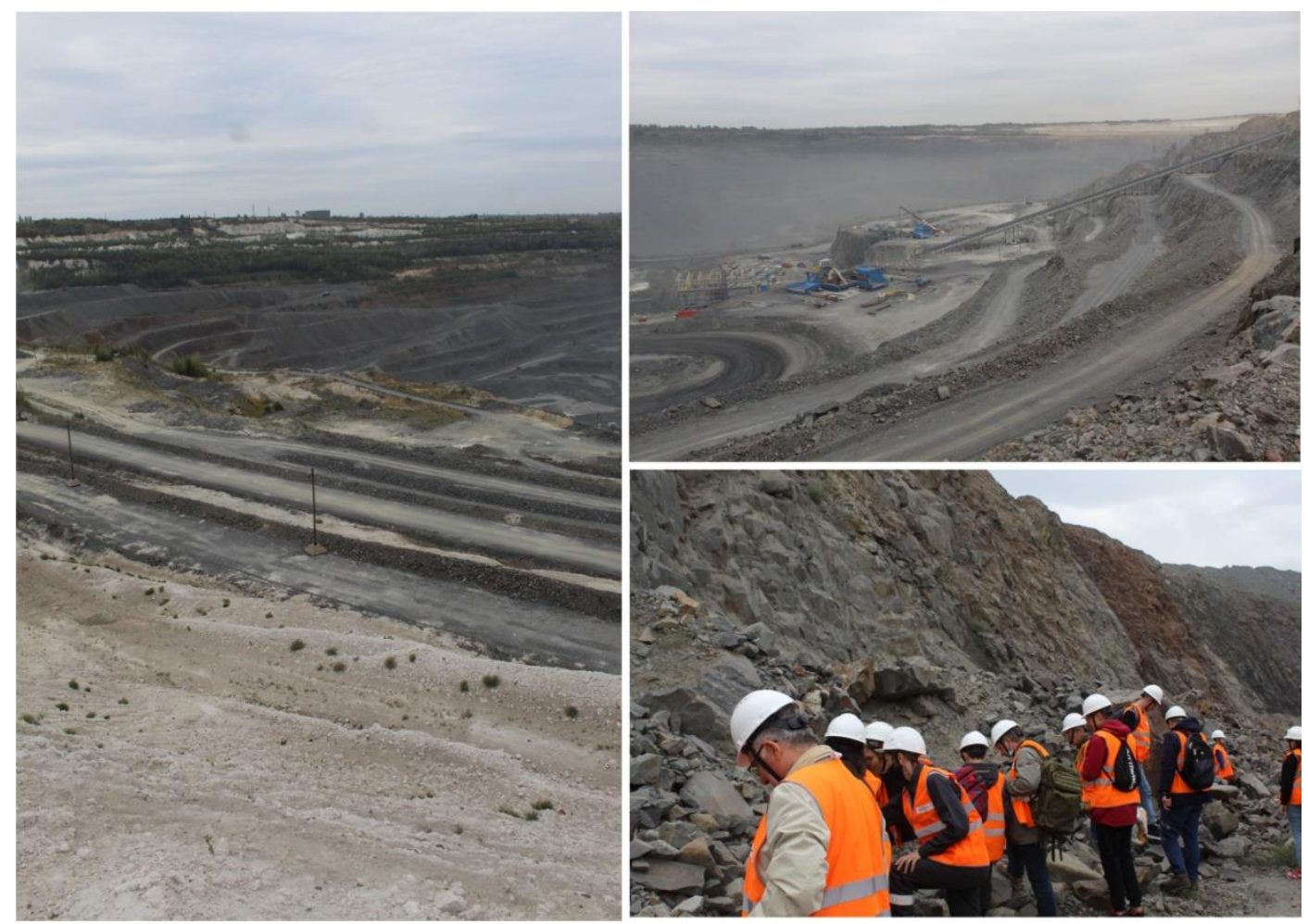

Рис. 2. Экскурсия для участников совещания на Лебединский горно-обогатительный комбинат, г. Губкин, Белгородская область.

[Fig. 2. Excursion for the meeting participants to the Lebedinsky mining and processing plant in Gubkin, Belgorod Region.] 


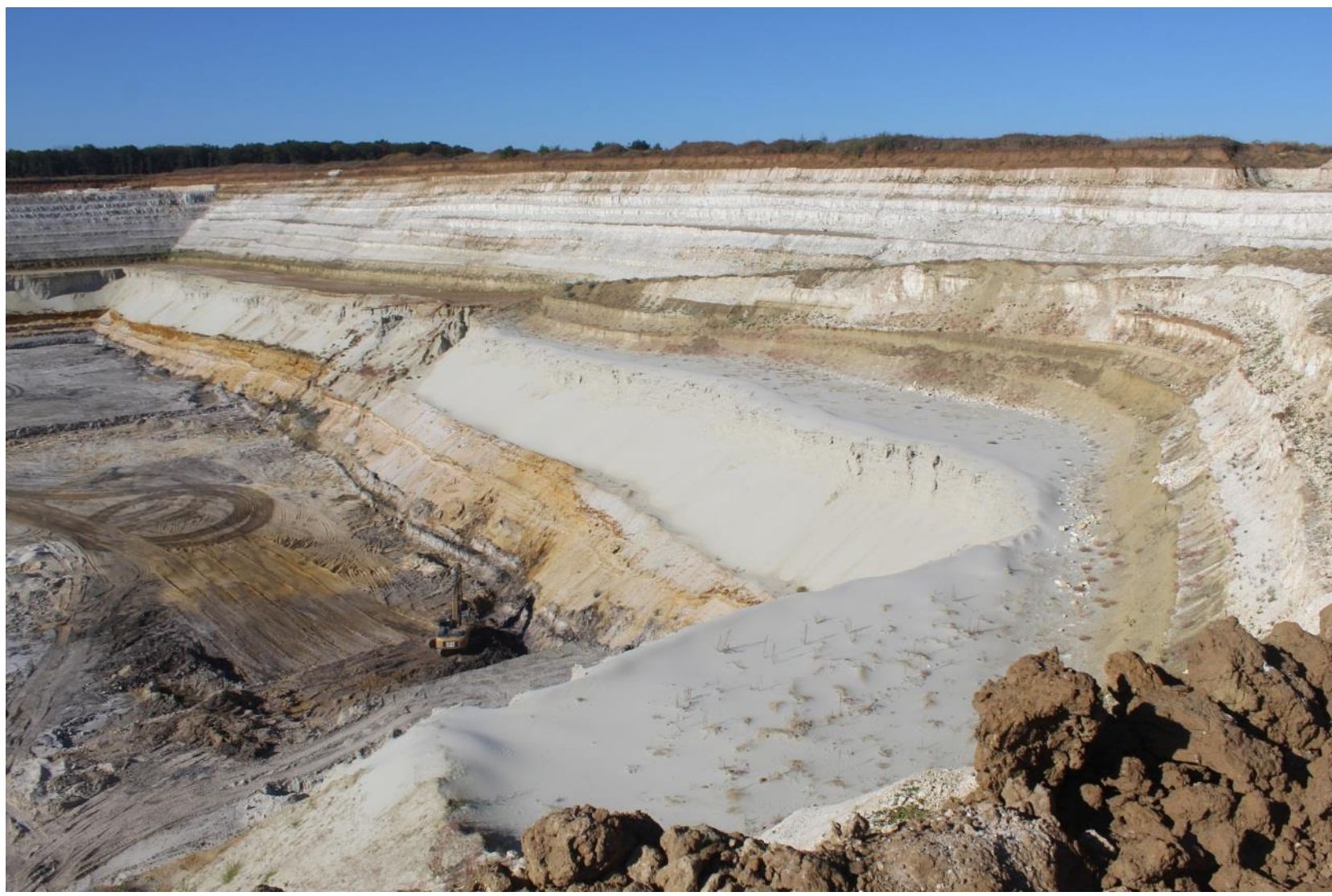

Рис. 3. Экскурсия для участников совещания на карьер "Средний", п. Латное, Воронежская область.

[Fig. 3. Excursion for the meeting participants to the Sredny quarry in Latnoe, Voronezh Region.]

Следует отметить хорошую организацию и большой познавательный интерес этих экскурсий. Ведущими учеными из числа участников проведены открытые лекции для студентов геологического факультета ВГУ и заинтересованных лиц.

Особенностью настоящего Совещания было одновременная работа в режиме онлайн и офлайн в формате видеоконференции. Одновременно шла запись выступлений, которые впоследствии размещены на странице YouTube. Совещание проходило при поддержке платформы геовебинара.

Записи трансляции Совещания РКВ-2020, Воронеж, 2021: 13 сентября

https://www.youtube.com/watch?v=2XwcOrW48rk

14 сентября https://youtu.be/7ge xEsyVLA

16 сентября https://youtu.be/DDxYXz0r-vQ ).

Материалы Совещания размещены в открытом доступе https://drive.google.com/file/d/12dYMkkddeEOrn5MKbYyX7vwfcC2j6pg/view?usp=sharing

С приветственным словом к участникам совещания выступили проректор Воронежского университета проф. Ю. А. Бубнов, декан геологического факультета проф. В. М. Ненахов, Председатель НС по проблемам литологии и осадочных полезных ископаемых ОНЗ РАН д-р геол. мин. наук Ю. О. Гаврилов, ведущий научный сотрудник ИГЕМ РАН д-р геол. мин. наук А. В. Лаломов, Председатель правления Воронежского отделения РОСГЕО д-р геол. мин. наук, проф. А. Н. Плаксенко (рис. 4).
В записи были заслушаны приветственные слова от академика Н. А. Шило (запись 2005 г.), профессоров, докторов наук, участников большинства Совещаний по РКВ А. Г. Баранникова (УГГУ, Екатеринбург), Б. М. Осовецкого и Б. С. Лунева (Пермский университет, Пермь) https://disk.yandex.ru/d/bOp1JPixpZfxiw

Работа совещания проходила по следующим направлениям.

1. Генетические типы месторождений россыпей и кор выветривания стратегического сырья.

2. Эволюция экзогенного рудогенеза.

3. Исследование системы «первичный источник коры выветривания - россыпь»; использование россыпей для поисков коренных месторождений.

4. Россыпи алмазов: сырьевое и поисковое значение.

5. Техногенно-минеральные образования и происходящие в них преобразования.

6. Технологии и экономика месторождений россыпей и кор выветривания.

7. Моделирование россыпеобразующих систем и процессов.

На пленарных и секционных заседаниях было заслушано и обсуждено 37 докладов. Материалы ещё 75 сообщений вошли в общий сборник статей по результатам проведенного совещания. Участники совещания представлены специалистами высшей квалификации, в основном докторами и кандидатами геолого-минералогических наук. 


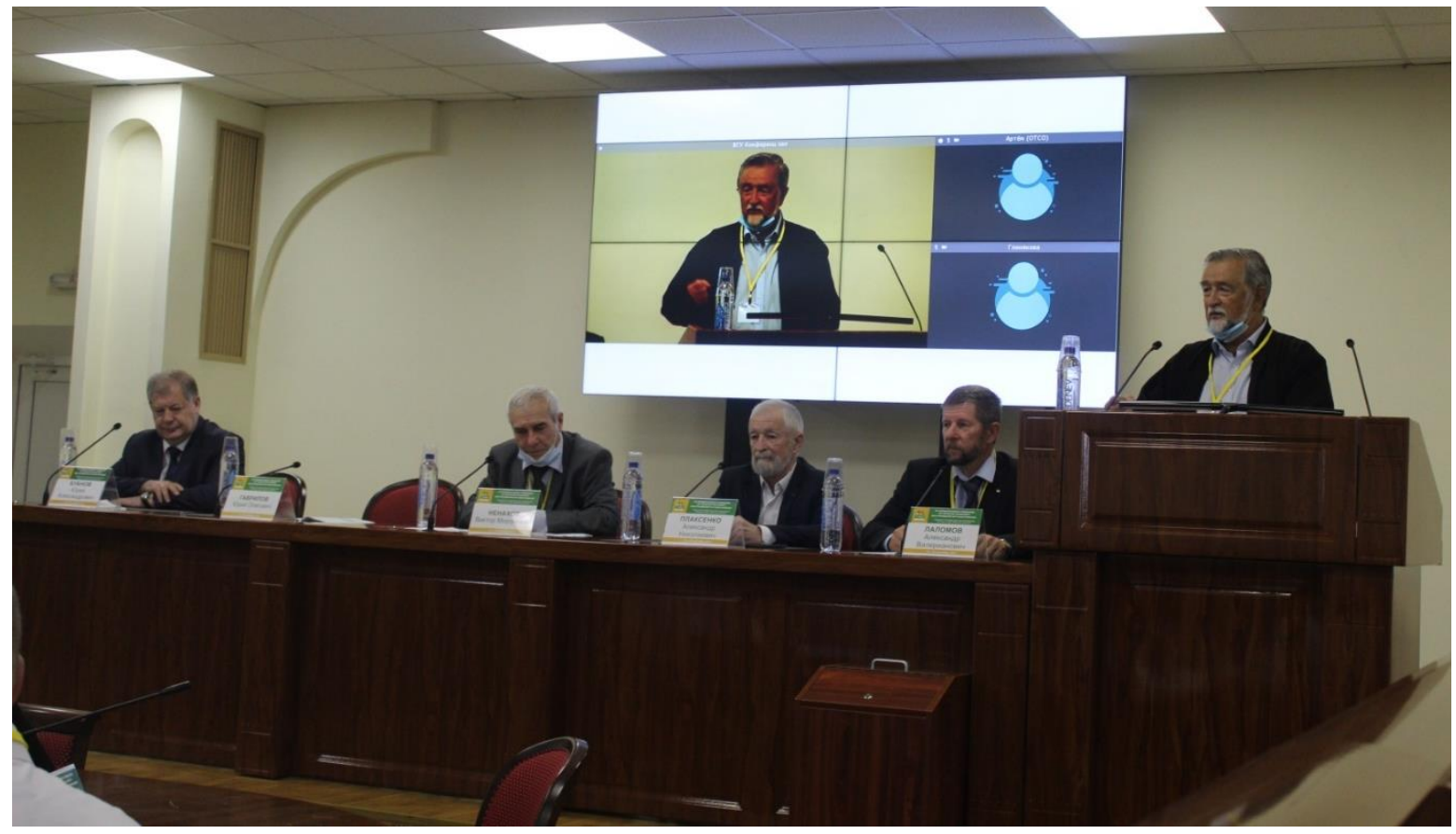

Рис. 4. Приветственное слово к участникам совещания от председателя НС по проблемам литологии и осадочных полезных ископаемых ОНЗ РАН д-ра геол. мин. наук Ю.О. Гаврилова.

[Fig. 4. Welcoming address by Yu. O. Gavrilov, DSc in Geology, Chairman of the Scientific Council on the Problems of Lithology and Sedimentary Minerals of the Earth Sciences Division of the Russian Academy of Sciences.]

На Совещание представлены программные доклады по истории и результатам работы российских научных центров, теоретические, методические и практические наработки по геологии россыпей, условиям формирования и вещественной характеристике месторождений кор выветривания, техногенно-минеральных образованиям за последние годы. Сделаны акценты на их изучение, освоение и экологическое состояние. В докладах показаны разработки по практически всем территориям России, где выявлены или разрабатываются такие месторождения: Карелия, Подмосковье, Центрально-Черноземный район, в том числе КМА, Урал, Тиман, Алтай, Салаир, Якутия, Тува, Хакассия, Красноярский край, Забайкалье, Приамурье, Дальний Восток как в пределах кристаллических структур щитов, горноскладчатых областей, так и осадочного чехла ВосточноЕвропейской и Сибирской платформ, внутренних и межгорных впадин. Сообщения приведены специалистами из российских городов: Москвы, Санкт-Петербурга, Воронежа, Перми, Екатеринбурга, Новосибирска, Ростована-Дону, Магадана, Якутска, Благовещенска, Петрозаводска, Мирного, Казани, Уфы, Владивостока, Сыктывкара. Значительное число докладов подготовлено представителями зарубежных стран (рис. 5).

Совещание явилось примечательным научным событием, в том числе для нашего университета. Сотрудники геологического факультета Воронежского университета внесли большой вклад в подготовку и организацию совещания, геологические экскурсии. В техническом плане много сделано проф. В. М. Ненаховым, доцентами А. В. Крайновым, С. В. Бондаренко, Г. С. Золотаревой. В проведении пленарных и секци- онных заседаний в качестве конвинеров приняли участие В. М. Ненахов, А. Д. Савко, А. В. Крайнов, А. В Черешинский.

Участниками совещания стали 14 ученых ВГУ. Ими сделано 11 докладов, в том числе два на пленарных и девять на секционных. В них рассмотрены эволюция корообразования и связанная с ней минерагения в фанерозое, девонские эффузивно-осадочные россыпи и вторичные каолины Воронежской антеклизы, бокситы карбона Курской магнитной аномалии, минералы-индикаторы кимберлитов нашего региона, цеолитоносные коры выветривания на карбонатных породах. Четыре доклада посвящено проблемам внедрения новых технологий извлечения драгметаллов из руд и образованных при их переработке техногенных отходов.

Участники XV Международного Совещания отметили:

- Высокий уровень организации и плодотворную научную работу совещания

- Профессионализм научных, методических и практических исследований, представленных на обсуждение совещания

- Положительный факт участия молодых ученых, специалистов, студентов в работе совещания.

- Высокий уровень информационной подготовки докладов, выступлений и презентаций

- Особенностью настоящего Совещания был очнозаочный и смешанный он-лайн и оф-лайн формат представления докладов и их обсуждения.

- Материалы докладов Совещания и обсуждение их транслировались в он-лайн формате, записаны и размещены на YouTube канале через платформу Геовебинара. 

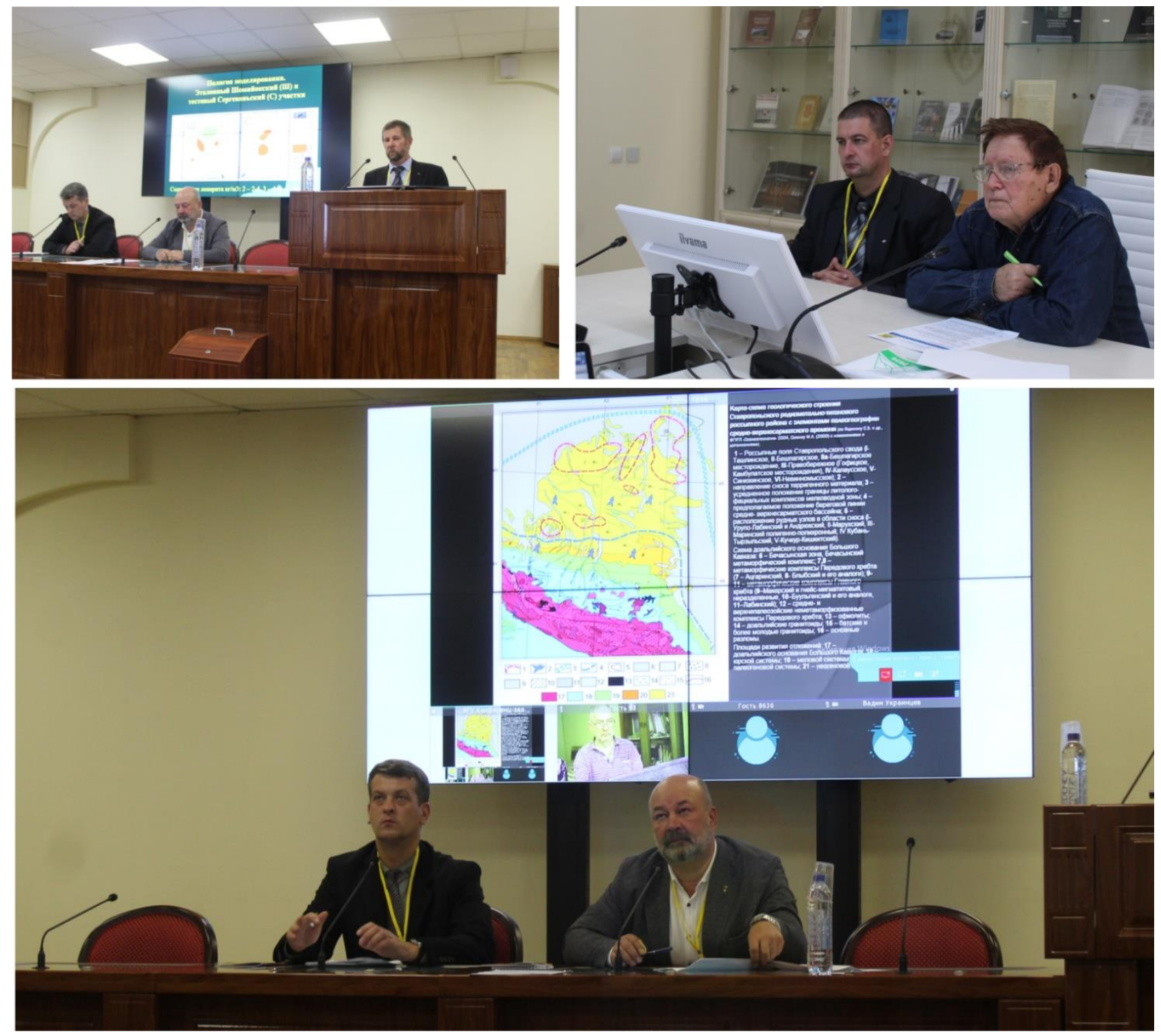

Рис. 5. Выступления участников XVI международного совещания по геологии россыпей и месторождений кор выветривания (PKB-2020)

[Fig. 5. Presentations by participants of the16th International Meeting on the Geology of Placers and Weathering Crust Deposits (RKV2020).]

Участники XV Международного Совещания рекомендовали:

1. Усилить внимание государственных федеральных и региональных структур к роли и месту россыпей, месторождений кор выветривания, техногенно-минеральным образованиям в развитии их минерально-сырьевой базы; в решении задач импортозамещения, развития новых технологий, включая нанотехнологии; расширении производственной базы действующих предприятий; решении экологических задач регионов; создании новых горно-промышленных агломераций на базе комплексных месторождений нетрадиционного типа (с тонким, мелким и нанозолотом, платиной, минералами редких земель, ниобия, титана, циркония и др.).

2. Разработать организационные системы для интеграции и систематизации знаний различных наук, специальностей, научных, учебных и производственных организаций (геологов, геофизиков, горняков, обогатителей, металлургов, химиков, биологов экологов, юристов и экономистов) при решении задач геологии россыпей, месторождений кор выветривания, техногенноминеральных

образований.

3. Учитывая возросшие потребности в глинистом сырье, основным продуцентом которого являются коры выветривания, включить в тематику будущих совещаний по РКВ материалы по геологии глин в рамках одной-двух секций.

4. Расширить возможности оценки минерально-сырьевого потенциала и путей практического использования знаний по управлению формированием техногенно-минеральных образований с заданными характеристиками минерального состава на действующих предприятиях. 


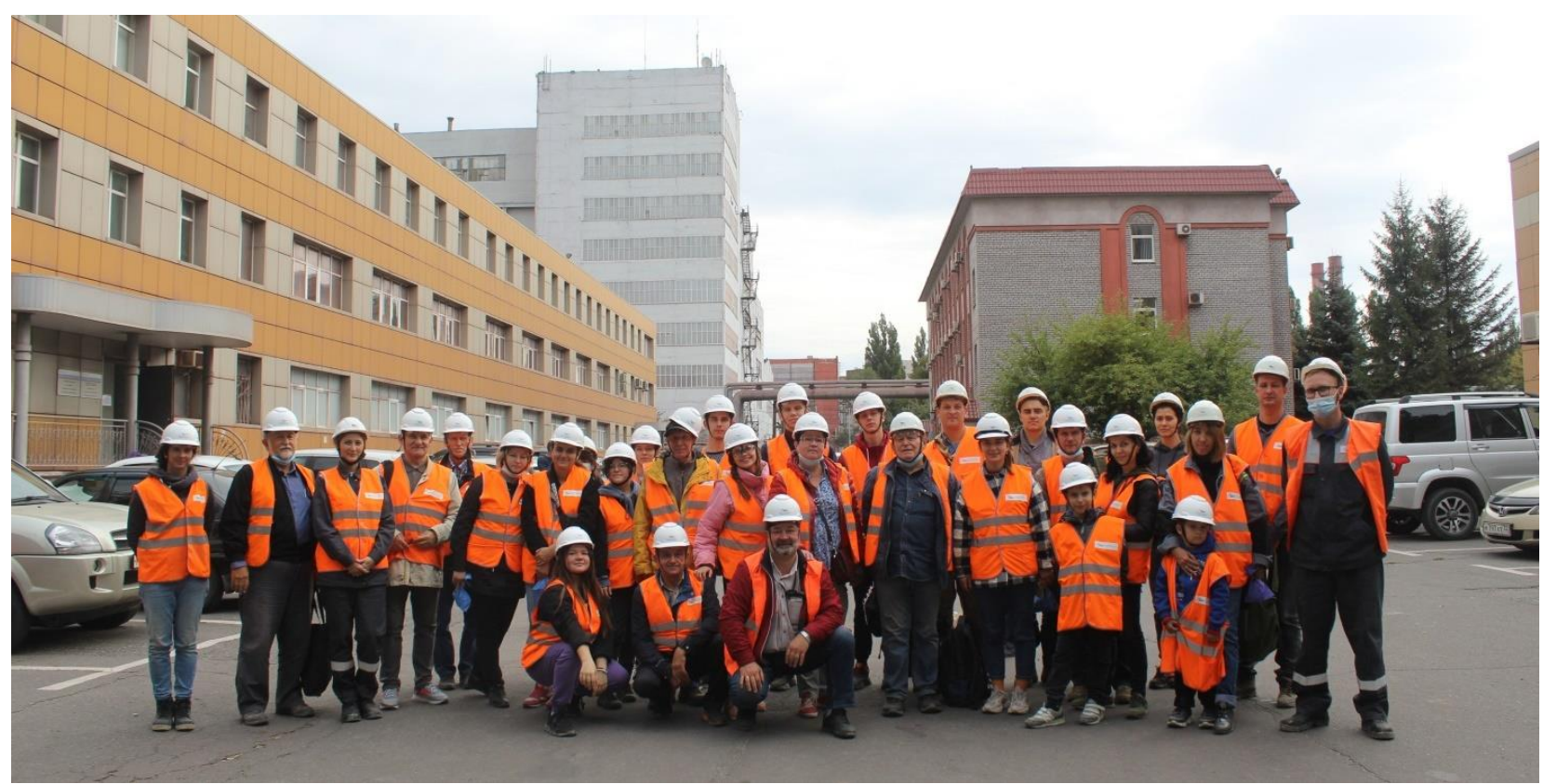

Рис. 6. Участники XVI международного совещания по геологии россыпей и месторождений кор выветривания (РКВ-2020) на территории Лебединского ГОК-а.

[Fig. 6. Participants of the 16-th International Meeting on the Geology of Placers and Weathering Crust Deposits (RKV-2020) at the territory of Lebedinsky mining and processing plant.]

5. Использовать стадиальный анализ при расшифровке генезиса россыпей и кор выветривания, возможностей влияния эндогенного фактора на изменения их вещественного состава для получения новой информации, необходимой при прогнозировании гипергенных месторождений.

6. С учетом новых достижений в области применения радиохронологических методов внедрить их в определения возраста кор выветривания и россыпей.

7. Обратить внимание на актуальность работ по развитию нового перспективного направления - наноминералогии благородных металлов, а также других видов минерального сырья.

8. Внедрять современные геоинформационные технологии (численные методы моделирования статических и динамических процессов и т.п.), дистанционные методы изучения, геофизические методы и современные системы обработки, интерпретации данных, геолого-производственные схемы, 3-D, 4-D модели геологических объектов.

9. Усилить исследования роли живого вещества в коро- и россыпеобразовании, наноминералогии, их влияния на природные и техногенные россыпи, месторождений кор выветривания, развивать направление биоминералогии.

10. Расширить сферы преподавательской деятельности в вузах с внедрением новых спецкурсов, лабораторных практикумов, основанных на использовании современного научного оборудования; развитии новых перспективных научных направлений с привлечением студентов; подготовки молодых научных и производственных кадров, специализированных в области геологии россыпей, геоморфологии, геологии и геохимии рыхлых отложений и кор выветривания и методов их изучения.

11. Провести XVII Совещание. Решение о месте и времени его проведения возложить на координационный Совет по россыпям, месторождениям кор выветривания и техногенно-минеральным образованиям.

Конфликт интересов. Авторы декларируют отсутствие явных и потенциальных конфликтов интересов, связанных с публикацией настоящей статьи.
Савко Аркадий Дмитриевич - д. г.-м. н., профессор, Воронежский государственный университет, Воронеж, Российская федерация; E-mail: savko@geol.vsu.ru; ORCID https://orcid.org/0000-0003-2133-3317

Овчинникова Марина Юрьевна - к.г.-м.н., преподаватель, Воронежский государственный университет, Воронеж, Российская федерация; E-mail: ovchinnikova@geol.vsu.ru; ORCID https://orcid.org/ 0000-0002-9143-0051

Авторы прочитали и одобрили окончательный вариант рукописи.
Arkady D. Savko -Dr. habil. in Geol.-Min, Professor, Voronezh State University, Voronezh, Russian Federation; E-mail: savko@geol.vsu.ru; ORCID https://orcid.org/0000-0003-21333317

Marina Yu. Ovchinnikova - PhD in Geol.-Min, lecturer, Voronezh State University, Voronezh, Russian Federation; E-mail: ovchinnikova@geol.vsu.ru; ORCID https://orcid.org/ 00000002-9143-0051

All authors have read and approved the final manuscript. 